\title{
Konsep Pornografi dan Pornoaksi Perspektif Hukum Islam
}

\author{
Jumliadi Rajab ${ }^{1}$, Zakirah Zakirah², Nursalam Nursalam³, \\ Muhammad Arsyam ${ }^{4}$, Andi Muhammad Shaleh Alwi 5 \\ ${ }^{1}$ Sekolah Tinggi Agama Islam (STAI) Darul Dakwah Wal-Irsyad (DDI) Kota Makassar, Indonesia \\ Email: jumliadirajab87@gmail.com \\ ${ }^{2}$ Institut Agama Islam Negeri (IAIN) Sultan Amai Gorontalo , Indonesia \\ Email: zakirahira17@gmail.com \\ ${ }^{3}$ Sekolah Tinggi Agama Islam (STAI) Darul Dakwah Wal-Irsyad (DDI) Kota Makassar, Indonesia \\ Email: salamnur094@gmail.com \\ ${ }^{4}$ Sekolah Tinggi Agama Islam (STAI) Darul Dakwah Wal-Irsyad (DDI) Kota Makassar, Indonesia \\ Email: arsyam0505@gmail.com \\ ${ }^{5}$ Sekolah Tinggi Agama Islam (STAI) Darul Dakwah Wal-Irsyad (DDI) Kota Makassar, Indonesia \\ Email: aleahm4d@gmail.com
}

\section{Abstrak:}

Fenomena pornografi dan pornoaksi dewasa ini telah mencapai perkembangan yang sangat pesat, sudah menyentuh setiap lapisan masyarakat tanpa terhalang oleh sekat-sekat geografis lagi. Bahkan masyarakat pedesaan yang secara geografis jauh dari kota yang diasumsikan sebagai sentra pornografi dan pornoaksi pun tak luput terjamah.

\section{Kata Kunci: Pornografi, Pornoaksi, Hukum Islam}

\section{PENDAHULUAN}

Mengapa pornografi dan pornoaksi dapat berkembang sedemikian pesat? Tentu banyak faktor yang melatarbelakanginya. Antara lain misalnya model busana yang masih menampilkan aurat. ${ }^{1}$ Media massa baik elektronik maupun cetak, termasuk juga (terutama) internet, tentu saja ikut andil dalam penyebaran pornografi dan pornoaksi. Sebab pornografi adalah substansi dalam media massa atau alat komunikasi yang dibuat untuk menyampaikan gagasan tentang seks, cabul atau erotika. Biasanya aksi porno digambarkan dengan lukisan atau gambar yang kemudian dikonsumsi publik lewat media cetak. Sedangkan pornoaksi adalah perbuatan, sikap, perilaku, gerakan tubuh ataupun suara yang erotis dan sensual, baik yang dilakukan dengan sengaja ataupun tidak sengaja, baik secara perseorangan atau kelompok.

Meski tidak sepenuhnya disebabkan oleh media massa, namun suguhan berita serta tayangan yang mengusung tema seksualitas berikut derivasinya secara tak langsung telah memantik imajinasi publik tentang pornografi dan pornoaksi. Belum

\footnotetext{
${ }^{1}$ Fungsi pakaian mula-mula tidak lebih dari untuk menutup badan dan melindunginya dari ancaman bahaya, tetapi ketika peradaban umat manusia semakin maju, fungsi pakaian pun juga menjadi bertambah yaitu untuk perhiasan dan meningkatkan kecantikan (al-tajammul wa al-tazayyun), keelokan, kecantikan dan ketampanan pada pakaian ini berbeda dari satu komunitas ke komunitas lainya.
} 
lagi internet, situs-situs porno begitu gampang diakses tanpa filter yang ketat jelas menjadi media efektif bagi mewabahnya pornografi dan pornoaksi.

Menurut sebuah penelitian, di seluruh dunia ada sekitar 26.000 situs porno. Jumlah ini diperkirakan akan terus bertambah, dengan 1.500 situs porno baru setiap bulannya. Situs porno lokal saja tidak kurang dari 1100 buah. Dus, buku, gambar, dan VCD porno juga tak sulit ditemukan. Dengan kepungan arus pornografi dan pornoaksi tersebut, siapa yang mampu menjamin masyarakat di berbagai lapisan tidak akan tenggelam dalam pusaran terkutuk itu. Akhirnya, disadari atau tidak, masyarakat pun melakukan hal yang mengarah ke bentuk pornografi dan pornoaksi. Oleh sebab itulah, dapat dimengerti mengapa angka pemerkosaan terus meningkat belakangan ini. Setidaknya berita pemerkosaan yang terus saja berulang di berbagai daerah dengan beragam motifnya makin menguatkan sinyalemen itu. Pada kisaran satu dasawarsa silam saja, di Indonesia rata-rata terjadi 5 sampai 6 wanita diperkosa setiap harinya. ${ }^{2}$ Tak menutup kemungkinan data ini bertambah secara drastis dewasa ini.

Sebuah penelitian di Ontario Kanada membuktikan, 77\% dari pelaku pemerkosaan sodomi (pria) dan $87 \%$ pemerkosa wanita mengaku menonton secara rutin bacaan dan tontonan porno. Liberalisasi pornografi di AS, Inggris, dan Australia telah meningkatkan angka pemerkosaan. Dr. Mary Anne Layden, Direktur pendidikan University of Pennsylvania Health System, menyatakan bahwa selama menangani pelaku dan korban kekerasan seksual selama 13 tahun, tak satu pun kasus yang tidak diakibatkan oleh pornografi. ${ }^{3}$ Meski terdapat perbedaan yang cukup signifikan dengan Indonesia, namun pada substansinya penelitian itu juga bisa digunakan sebagai parameter untuk menjawab kenapa kasus pemerkosaan di negara ini terus meningkat. Maka siapakah yang harus disalahkan bila perilaku yang mengarah pada pornografi dan pornoaksi sudah sedemikian menggurita di wilayah publik? Namun tak etis jika menumpahkan kesalahan kepada pihak tertentu. Justru masyarakat sendiri yang mesti secara tegas mengevaluasi dirinya atas semua itu. Hanya saja, sampai saat ini masih terjadi silang pendapat tentang pornografi dan pornoaksi itu sendiri. Hal itu muncul karena perbedaan sudut pandang dalam memahami pornografi dan pornoaksi.

\footnotetext{
${ }^{2}$ Republika, 29/5/1994.

${ }^{3}$ Buletin al-Islam edisi 305 tahun VI 19 Mei 2006.
} 


\section{PEMBAHASAN}

\section{A. Pengertian Pornografi dan Pornoaksi}

Porno atau ketelanjangan mempunyai dua pengertian yaitu, ketelanjangan yang disajikan dalam media cetak dan elektronik, dan ketelanjangan yang disajikan secara langsung dengan berbagai gaya. Kategori pertama dinamakan "pornografi", sementara kategori kedua dinamakan "pornoaksi".

Pornografi berasal dari bahasa Yunani, porne artinya pelacur dan graphen artinya ungkapan. ${ }^{4}$ Menurut Kamus Besar Bahasa Indonesia kata porno berasal dari kata porne yang berarti cabul, sedangkan pornografi menurut kamus tersebut adalah:Pornografi adalah penggambaran tingkah laku secara erotis dengan lukisan atau tulisan untuk membangkitkan nafsu birahi. Ada juga yang mengatakan bahwa Pornografi adalah bahan yang dirancang dengan sengaja dan semata-mata untuk membangkitkan nafsu birahi dan seks. ${ }^{5}$ Berdasarkn dari asal kata pornografi, maka bisa diartikan sebagai ungkapan yang berhubungan dengan ekspresi mesum wanita pelacur.Sedangkan istilah pornoaksi diperkenalkan oleh Majelis Ulama Indonesia (MUI) melalui Fatwa MUI Nomor 287 Tahun 2001.

Kementrian Pemberdayaan Perempuanmenerbitkan sebuah brosur yang isinya menyabutkan bahwapornografi adalah produk visualisasi seperti gambar, foto, film dan jenis lainnya yang mengekploitasi seks dengan cara asusila yang melecehkan harkat dan martabat wanita, melanggar moral, ajaran agama, adat istiadat dan tradisi. Dalam perkembangannya istilah pornografi mengalami perluasan arti menjadi pornoaksi, sehingga yang dikategorikan porno tidak lagi dalam bentuk gambar seperti foto atau film, tetapi dalam wujud nyata berupa tindakan. ${ }^{6}$

${ }^{4}$ Abu Abdurrahman Nusantari, Menepis Godaan Pornografi (Cet. II; Jakarta: PT Darul Falah, 2005), h. 28. Lihat juga, Neng Djubaedah, Pornografi dan Pornoaksi Ditinjau dari Hukum Islam (Cet. II; Jakarta Timur: Kencana, 2004), h. 138. Sumber: Situs.ikadi.org.

${ }^{5}$ Pusat Bahasa Departemen Pendidikan Nasional, Kamus Bahasa Indonesia (Jakarta: Departement Pendidikan, 2008 M), h. 696

${ }^{6}$ Dharma wanita persatuan, 2002, Arti Pornografi dan pornoaksi.http://www.dwp.or.id/article.php. (Diakses 20/04/2018) 
Menurut Mustanyir,pornografi dapat dipahami dalam tiga pengertian.Pertama, kecabulan yang merendahkan derajat kaum wanita.Kedua,merosotnya kualitas kehidupan yang erotik dalam gambar-gambar yang jorok, kosakata yang kasar, dan humor yang vulgar. Ketiga, mengacu pada tingkah laku yang merusak, yang terkait dengan mental manusia. ${ }^{7}$

\section{B. Pornografi dan Pornoaksi dalam Perspektif Hukum Islam}

Agama ditujukan sebagai pengatur dan penyelaras kehidupan manusia menuju kebahagiaan, agama bukan diproyeksikan sebagai pemasung kebebasan, kreatifitas maupun peradaban manusia.Pornografi dalam ajaran agama Islam, marupakan suatu bentukpelanggaran yang menyalahi nilai dan norma yang telah diatur didalamnya.Islam lebih mengenal hal itu dengan istilah aurat. Aurat seharusnya tertutup dari pandangan siapapun yang melihatnya, akantetapi pada kenyataannya, aurat menjadi hal yang biasa untuk diperlihatkan. Ajaran agamaIslam menjelaskan bahwa memperlihatkan aurat adalah suatuperbuatan yang mengarah pada perzinahan.Dan zina secara eksplisit dilarang dalam Islam.Al-Qur'an dengan jelas menyebutkan larangan mendekati zina terlebih lagi melakukannya dengan ancaman hukuman yang berat.Sebagaimana firman Allah dalam QS al-Isra'/17: 32.

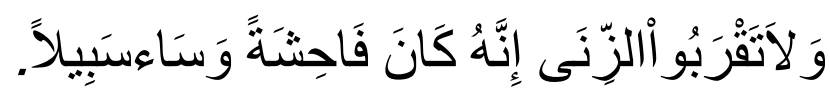

Terjemahnya:

"Dan janganlah kamu mendekati zina; sesungguhnya zina itu adalah suatu perbuatan yang keji dan suatu jalan yang buruk."

Allah swt.akan memberikan hukuman yang berat bagi orang yang melakukan perzinahan. Allahberfirman dalam QSal-Nur/24: 2.

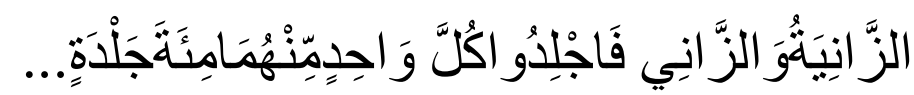

${ }^{7}$ Rizal Mustanyir, "Refleksi Filosofis atas Pornografi dan Pornoaksi,” Tarjih, Edisi 5 Januari 2003.

${ }^{8}$ Departemen Agama RI., al-Qur'an dan Terjemahnya (Madinah al-Munawwarah: Yayasan Penyelenggara Penterjemah al-Qur'an, Mujamma‘ Khadim al-Haramain al-Syarifain, al-Malik Fahd li Ṭiba'ah al-Muṣhaf al-Syarif, 1418 H), h. 429. 
Terjemahnya:

"Perempuan yang berzina dan laki-laki yang berzina, maka deralah tiap-tiap seorang dari keduanya seratus kali dera,..."

Konsep dasar ajaran agama adalah mewujudkan kemaslahatan manusia yang terkonstruk dalam maqasid al-syari'ah salah satunya adalah hifz al-nafs (menjaga kelestarian masyarakat manusia).Dorongan seksual dan kelestarian masyarakat adalah dua hal yang sangat terkait erat, tanpa adanya dorongan seksual, kepunahan manusia berada didepan mata. Dan dorongan seksual tercipta dengan beban tanggung jawab yakni melestarikan manusia dengan cara seks yang halal menurut syariat Islam.

Menurut ajaran Islam, tubuh manusia merupakan amanah Allah bagi pemilik tubuh yang wajib dipelihara dan dijaga dari segala perbuatan tercela, perbuatan yang merugikan, baik bagi diri pemilik tubuh itu sendiri maupun masyarakat demi keselamatan hidup dan kehidupannyadi dunia dan akhirat.

Tubuh sebagai amanah dari Allah swt.yang wajib dipelihara oleh setiap insan, antara lain telah diatur tata busana dan tata pergaulan dalam keluarga dan masyarakat, baik bagi laki-laki maupunwanita. Allah berfirman dalam QS al-Ahzab/33: 59.

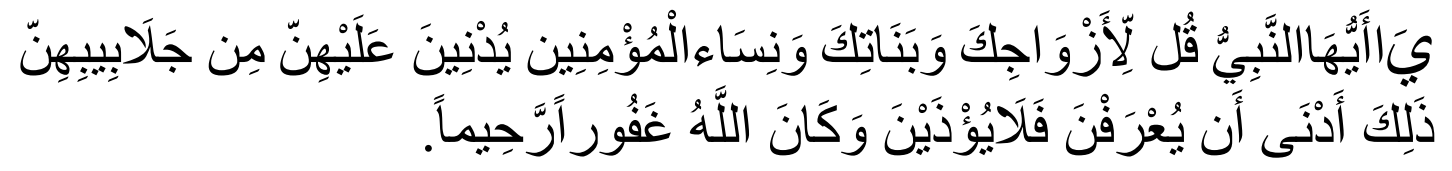

Terjemahnya:

"Hai Nabi katakanlah kepada isteri-isterimu, anak-anak perempuanmu dan isteri-isteri orang mu'min: "Hendaklah mereka mengulurkan jilbabnya ke seluruh tubuh mereka". Yang demikian itu supaya mereka lebih mudah untuk dikenal, karena itu mereka tidak diganggu.Dan Allah adalah Maha pengampun lagi Maha penyayang."10

Pencegahan terjadinya perzinahan itu bermula dari penjagaan pandangan dari aurat.Allah berfirman dalamQSal-Nur/24: 30 .

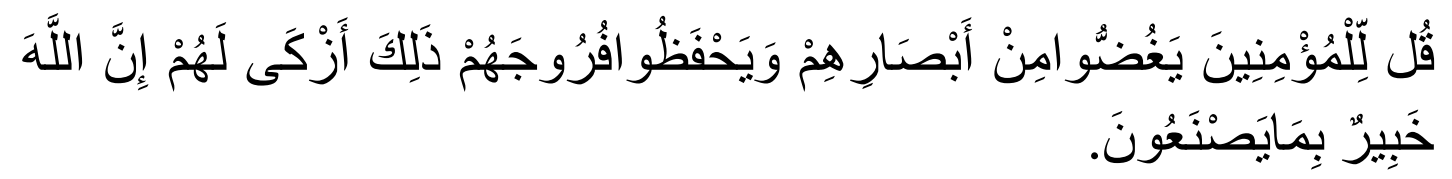

${ }^{9}$ Departemen Agama RI, al-Qur'an dan Terjemahnya, h. 543.

${ }^{10}$ Departemen Agama RI, al-Qur'an dan Terjemahnya, h. 678. 
Terjemahnya:

"Katakanlah kepada orang laki-laki yang beriman: Hendaklah mereka menahan pandangannya, dan memelihara kemaluannya; yang demikian itu adalah lebih suci bagi mereka, sesungguhnya Allah Maha Mengetahui apa yang mereka perbuat."11

Ayat tersebut menjelaskan bahwa seorang mukmin dan mukminah itu dilarang untuk melihat hal-hal yang diharamkan.Hal itu dimaksudkan untuk menjaga dirinya dari kerusakan (anjuran menjaga aurat) dan untuk menjaga kehormatan orang lain. Namun jika pandangan terarah pada sesuatu yang diharamkan tanpa adanya unsur kesengajaan, maka secepat mungkin untuk mengalihkan pandangan.

Konsep hukum Islam mengenai pornografi dan pornoaksi menggunakankaidah maslahah mursalah yang berasaskan keadilan dan sadd al-zri'ah (mencegah kemungkinan adanya kerusakan). Adanya siyasah syar'iyyah, yakni kebijaksanaan membuatmasyarakat lebih dekat dan gemar pada kebajikan, menjauhi danmembenci keburukan dan kerusakan dimaksudkan untuk merealisasikankemaslahatan manusia.

\section{Batasan Pornografi dan Pornoaksi Menurut Islam}

Islam memberikan pengertian yang jelas tentang pornografi dan pornoaksi.Secara fikih menyaksikan secara langsung aurat seseorang yang bukan haknya (pornoaksi) adalah haram, kecuali untuk tujuan yang diperbolehkan oleh syariat. Misalnya memberi pertolongan medis, ini akan berlaku juga pada para pembuat pornografi (kameramen, pengarah gaya, suradara dan lain sebagainya). Islam menghargai kebebasan seseorang untuk berekspresi, namun dalam koridor syariat, Islam juga mengakui bahwa setiap manusia memiliki naluri seksual namun mengarahkannya agar disalurkan pada cara-cara yang sesuai dengan syariat. Islam sebagai pencetus ideologi memiliki cara-cara yang khas untuk menyelesaikan permasalahan yang dihadapi manusia, tanpa menelantarkan kebutuhannya yang lain dan mengabaikan kebutuhan manusia lainnya dalam masyarakat.Oleh karena itu, Islam tidak sekedar menetapkan agar tak ada seorang pun dalam wilayah Islam yang mengumbar aurat kecuali dalam hal-hal yang dibenarkan syariat, namun Islam juga memberikan satu perangkat agar ekonomi berjalan dengan benar, sehingga tak perlu ada orang yang mencari nafkah dalam bisnispornografi dan pornoaksi. ${ }^{12}$

\footnotetext{
${ }^{11}$ Departemen Agama RI, al-Qur'an dan Terjemahnya, h. 548.

${ }^{12} \mathrm{http}: / /$ mujahid.com/pornografi-dan-pornoaksi. (Diakses 20/04/2018)
} 


\section{Tindak Pidana Pornografi dan Tindak Pidana Pornoaksi di Indonesia}

Masalah pornografi dan pornoaksi di Indonesia telah melampaui ambang toleransi dan merusak akhlak bangsa, namun penyelesaian terhadap masalah pornografi belum sesuai dengan yang diharapkan.Kesulitan dalam mengatasi tindak pidana pornografi dan pornoaksi antara lain disebabkan oleh adanya pengertian dan penafsiran yang berbeda terhadap pasal-pasal KUHP yang mengatur masalah pornografi dan dahulu masyarakat lemah dalam merespon pornografi dan pornoaksi.

Faktor penyebab dari kelemahan masyarakat antara lain disebahkan oleh faktor politik, di bidang keagamaan yang terlihat dalam politik, pendidikan agama di sekolahsekolah tinggi.KUHP sendiri tidak merumuskan pengertian pornografi, namunberdasarkan tafsiran atas pasal 281, pasal 282, pasal 283, pasal 532, pasal 534 dan pasal 535, maka penegrtian "pornografi" dapat disimpulkan dari pasal-pasal tersebut, demikian pula dalam pasal 411 sampai dengan pasal 416, pasal 420 dan pasal 422 RUU KUHP istilah pornografi (pornoaksi) tidak disebutkan dan dirumuskan secara eksplisit. Karena itu pengertian pornografi dan pornoaksi menurut RUU KUHP juga dpaat disimpulkan dari pasal-pasal yang mengatur tentang tindak pidana kesusilaan.

\section{E. Dampak Pornografi dan Pornoaksi}

Pornografi dan Pornoaksi akan memberikan dampak negatif bagi masyarakat pada umumnya, sehingga masyarakat perlu diberikan pembelajaran tentang hal-hal yang dapat ditimbulkan akibat adanya pornografi dan pornoaksi. Hal ini karena semakin maraknya aksi-aksi porno, baik dalam kehidupan sehari-hari maupun dalam media-media pada umumnya.Diantara dampak pornografi dan pornoaksi itu adalah:

1. Bagi anak kecil yaitu mereka akan sulit berkonsentrasi kembali dalam pelajaran sekolahnya, misalnya setelah melihat gambar-gambar porno melalui media internet.

2. Bagi orang dewasa yaitu dapat melakukan tindakan pemerkosaan untuk memenuhi hawa nafsunya, misalnya setelah menonton film-film beradegan syur. Hal ini tentuakan merugikan orang lain di sekitarnya. 
3. Bagi generasi muda yaitu baik terhadap perilaku, moral (Akhlak), maupun terhadap sendi-sendi serta tatanan keluarga dan masyarakat beradab, seperti pergaulan bebas, perselingkuhan, kehamilan dan kelahiran anak diluar nikah, aborsi, penyakit kelamin, kekerasan seksual, dan lain sebagainya.Masalah ini tidak lagi menyangkut sejumlah kecil orang (misal keluarga) tetapi sudah menyangkut lingkungan sekitar dan kehidupan bermasyarakat. Masalah ini tidak lagi merugikan satu kelompok saja (hanya keluarga yang merasa dipermalukan) tetapi juga lingkungan dimana orang tersebut (yang melakukan tindakan pornografi dan pornoaksi) berasal. Dikarenakan dampaknya yang semakin fatal, status masalah pornografi dan pornoaksi ini tidak diam di tempat sebagai public problem, tetapi sudah beralih lagi menjadi policy problem.

Sedangkan dalam Islam telah ditegaskan bahwa batasan aktivitas yang akan membawa kemanfaatan adalah apabila sesuatu aktivitas tersebut sesuai dengan ketentuan yang tertuang dalam syariat. Dan sebaliknya apabila sesuatu aktivitas tersebut tidak bersumber dan bertentangan dengan syariat dapat dipastikan aktivitas tersebut akan membawa dosa. Dan suatu keyakinan yang telah terhujam di dalam dada dan keimanan seorang muslim adalah segala apa yang mereka lakukan akan dipertanggungjawabkan di akhirat kelak. Demikian juga kebebasan dalam beraktivitas di luar ketentuan syariat misalnya pornogafi dan pornoaksi dapat dipastikan telah bermaksiat atau membangkang kepada syariat Allah danakan mendapatkan sanksi yang keras di Hari Pembalasan nanti. ${ }^{13}$

\section{F. Upaya Pencegahan dan Pemberantasan Pornografi dan Pornoaksi}

Globalisasi telah menghapus sekat-sekat yang ada dalam masyarakat internasional maupun merembes kepada masyarakat dalam satu negara. Hal yang nampak jelas adalah terjadinya pertemuan antar budaya yang telah melahirkan dua mata pisau, di satu sisi berdampak positif, namun di sisi lain berdampak negatif.

\footnotetext{
${ }^{13}$ Irama Pena Zaida, Analisis Fatwa Mui Tentang Pornografi Dan Pornoaksi. http://anizaida89.blogspot.co.id/2011/09/analisis-fatwa-mui-tentang-pornografi.html. (Diakses pada 21/04/2018)
} 
Negara-negara timur, khususnya Indonesia sangat terkenal dengan bangsa yang sopan santun, lebih beretika, dan sangat memegang norma-norma terutama norma agama. Berkat kemajuan teknologi dan informasi, maka masuklah pengaruh dari negara-negara lain terutama masuknya budaya dari negara-negara Barat. Hal inilah yang kemudian menjadikan aktivitas pornografi dan pornoaksi kian merebak.

Di samping itu, budaya patriarkhi (menempatkan perempuan sebagai objek) yang masih kuat, menjadi asumsi masyarakat bahwa pelaku pornografi dan pornoaksi hanya perempuan, sementara pelaku laki-laki sering terabaikan. Realitasnya, dalam pornografi dan pornoaksi, perempuan adalah sasaran atau objek bahkan eksploitasi sampai ke arah kekerasan seksual sehingga perempuan lebih banyak yang dirugikan karena perempuan menjadi objek pemaksaan, pelecehan dan eksploitasi seksual. Oleh sebab itu, sudah semestinya ada upaya maksimal sebagai bangsa yang berbudaya secara bersama-sama bisa melindungi kaum perempuan dari jebakan-jebakan bernuansa pornografi dan pornoaksi.

Melihat efek yang ditimbulkan pornoaksi dan pornografi, sudah seharusnya untuk segera melakukan tindakan-tindakan proaktif untuk mencegah dan memberantas aktivitas ini. Hal inilah yang kemudian mendapat kepedulian dari pihak Majelis Ulama Indonesia (MUI). Melalui Keputusan Fatwa Nomor 287 tahun 2001 tentang pornografi dan pornoaksi pada tanggal 22 Agustus 2002, merekomendasikan untuk mendesak semua penyelenggara negara untuk menetapkan peraturan perundang-undangan tentang pornografi dan pornoaksi. ${ }^{14}$

Upaya ini menuai hasil dengan disahkannya UU RI No. 44 tahun 2008 tentang Pornografi. Awalnya, inisiatif DPR yang membentuk Pansus RUU APP untuk membahas RUU APP perlu mendapat apresiasi semua pihak yang prihatin terhadap dekadensi moral generasi muda bangsa yang sudah sangat akut. Meskipun KUHP telah mengatur sanksi pidana asusila, namun dalam prakteknya pornografi/pornoaksi kian merajalela. Dibutuhkan undang-undang yang lebih represif untuk menghentikan tindak pidana tersebut sebab tindak pidana asusila dalam KUHP hanya termasuk

\footnotetext{
${ }^{14}$ Departemen Agama RI, Himpunan Majelis Ulama Indonesia, h. 304.
} 
tipiring (tindak pidana ringan) dengan ancaman hukuman maksimal 18 bulan atau pidana denda maksimal Rp. 4.500 (empat ribu lima ratus rupiah). ${ }^{15}$

UU RI No. 44 tahun 2008 tentang Pornografi ini diharapkan mampu melindungi kaum perempuan dan juga anak-anak serta mampu mengayomi segenap kepentingan kaum perempuan di wilayah hukum Indonesia yang mempunyai beraneka ragam etnis, tradisi dan budaya sehingga ketika telah menjadi undangundang, semua komponen bangsa akan mematuhinya dengan segala konsekuensi hukum yang mengikat di dalamnya.

Pencegahan juga dapat dilakukan melalui jalur pendidikan, terkhusus penekananya pada pendidikan agama. Agama merupakan salah satu faktor utama yang dapat memberantas, mencegah, menanggulangi pornografi maupun pornoaksi, maka langkah-langkah yang dapat dilakukan oleh lembaga pendidikan di antaranya adalah: Menambah jam tatap muka materi pelajaran agama dan memasukkan nilainilai agama kepada seluruh materi pelajaran; Mengajukan program tayangan Pendidikan Umum dan Pendidikan Agama ke media Televisi; Menertibkan cara berpakaian dan baju sekolah peserta didik; Menambah atau memberikan kegiatan ekstra kurikuler di sekolah. Langkah-langkah dan kegiatan tersebut bertujuan untuk : Meningkatkan keimanan dan ketaqwaan; Meningkatkan kualitas moral dan akhlak; Mencerdaskan kualitas fisik, mental, moral, akhlak dan sosial; Mencegah terjadinya dekadensi moral dan akhlak peserta didik.

Peran media massa juga sangat diharapkan untuk mencegah dan memberantas pornoaksi dan pornografi. Fungsi yang sangat strategis membentuk opini publik yang kondusif kearah pencegahan dan pemberantasan yaitu dengan menampilkan tayangan-tayangan yang bermutu sesuai dengan citra budaya bangsa yang sopan dan beradab.

Dengan demikian, masalah pornografi dan pornoaksi merupakan tanggung jawab bersama karena pornoaksi dan pornografi adalah sebuah refleksi mengikisnya nilai-nilai luhur budaya bangsa serta dekadensi moral yang

\footnotetext{
${ }^{15}$ Pasal 282 ayat (1) KUHP, Andi Hamzah, h. 111.
} 
perlu dicermati dampak sosial psikologisnya. Bila hal ini dibiarkan, maka akan lahir sebuah generasi yang terlena dengan imajinasi pornoaksi dan pornografi yang kemudian akan membawa kepada kehancuran moral sehingga diperlukan kebijakankebijakan yang dapat memberantas pornoaksi dan pornografi.

\section{KESIMPULAN}

Berdasarkan pembahasan di atas, maka dapat disimpulkan bahwa:

1. Konsep hukum Islam mengenai pornografi dan pornoaksi menggunakan kaidah maslahah mursalah yang berasaskan keadilan dan sadd al-zri'ah (mencegah kemungkinan adanya kerusakan). Adanya siyasah syar'iyyah, yakni kebijaksanaan untuk membuat masyarakat lebih dekat dan gemar pada kebajikan, menjauhi dan membenci keburukan dan kerusakan, dimaksudkan untuk merealisasikan kemaslahatan manusia.

2. Pornografi dan Pornoaksi akan memberikan dampak negatif bagi masyarakat pada umumnya, sehingga masyarakat perlu diberikan pembelajaran tentang hal-hal yang dapat ditimbulkan akibat adanya pornografi dan pornoaksi tersebut.

3. Pencegahan juga dapat dilakukan melalui jalur pendidikan, terkhusus penekananya pada pendidikan agama. Agama merupakan salah satu faktor utama yang dapat memberantas, mencegah, menanggulangi pornografi maupun pornoaksi, maka langkah-langkah yang dapat dilakukan oleh lembaga pendidikan di antaranya adalah: Menambah jam tatap muka materi pelajaran agama dan memasukkan nilai-nilai agama kepada seluruh materi pelajaran, dll 


\section{DAFTAR PUSTAKA}

Buletin al-Islam edisi 305 tahun VI 19 Mei 2006.

Departemen Agama RI. al-Qur'an dan Terjemahnya. Madinah al-Munawwarah: Yayasan Penyelenggara Penterjemah al-Qur'an, Mujamma' Khadim al-Haramain al-Syarifain, al-Malik Fahd li Tiba'ah al-Mushaf al-Syarif, $1418 \mathrm{H}$.

Dharma wanita persatuan, 2002,Arti Pornografi dan pornoaksi.http://www.dwp.or.id/article.php.id=111. (Diakses 20/04/2018)

Djubaedah, Neng. Pornografi dan Pornoaksi Ditinjau dari Hukum Islam.Cet. II; Jakarta Timur: Kencana, 2004.

Hamzah, Andi., KUHP dan KUHAP, Jakarta: Rineka Cipta, 2000.

http://mujahid.com/pornografi-dan-pornoaksi. (Diakses 20/04/2018)

Mustanyir, Rizal. "Refleksi Filosofis atas Pornografi dan Pornoaksi," Tarjih, Edisi 5 Januari 2003.

Nusantari, Abu Abdurrahman. Menepis Godaan Pornografi. Cet. II; Jakarta: PT Darul Falah, 2005.

Pusat Bahasa Departemen Pendidikan Nasional, Kamus Bahasa Indonesia. Jakarta: Departement Pendidikan, 2008 M.

Republika, 29/5/1994.

Zaida, Irama Pena. Analisis Fatwa Mui Tentang Pornografi Dan Pornoaksi. http://anizaida89.blogspot.co.id/2011/09/analisis-fatwa-mui-tentang pornografi.html.(Diakses pada 21/04/2018)

Nursalam, N., Basri, A., \& Akbar, A. Implementasi Nikah Dalam Al-Qur'an (Studi Pendekatan Tafsir Maudu'i).

Arsi, A., Fail, W. O. N., \& Arsyam, M. (2021). Membangun Keluarga Yang Islami.

Arsyam, M., \& Alwi, A. M. (2020). MANAJEMEN HIDUP DALAM PERSPEKTIF ALQUR'AN.

Rifqi, N., Fajrin, M. F., \& Arsyam, M. (2021). Ibadah Sebagai Aspek Ritual Ummat Islam.

Fail, W. O. N., Putri, A. A., \& Arsyam, M. Kedudukan Dakwah Dan Amar Ma'ruf Nahi Munkar Dalam Ajaran Agama Islam.

Zakirah, Z., Arsyam, M., Altimory, \& Halwa, H. (2020, November 3). Rekonstruksi Wacana Poligami Berbasis Nalar Fiqhi Kontemporer. https://doi.org/10.31219/osf.io/z8epm

Arsyam, M., \& Sainuddin, I. H. Meraih Surga dengan Sabar dan Syukur.

Sapada, A. O. (2020). Mendidik Anak Menjadi Anak Sholeh.

Sapada, A. O., \& Arsyam, M. (2020). Ilmu Pengetahuan dan Teknologi Menurut Pandangan Islam.

Alwi, A. M. S. (2020). Wanita Karir Dalam Perspektif Pria Bugis.

Arsyam, M., \& Umar, K. (2020). MANUSIA SEBAGAI PENDIDIK PERPEKTIF ISLAM DAN BARAT. 